\title{
Diagnostic and ethical challenges in disorders of consciousness and locked-in syndrome: a survey of German neurologists
}

\author{
Katja Kuehlmeyer • Eric Racine • Nicole Palmour • \\ Eva Hoster • Gian Domenico Borasio • \\ Ralf J. Jox
}

Received: 17 December 2011/Revised: 14 February 2012/ Accepted: 15 February 2012/Published online: 10 March 2012

(C) The Author(s) 2012. This article is published with open access at Springerlink.com

\begin{abstract}
Diagnosis and decisions on life-sustaining treatment (LST) in disorders of consciousness, such as the vegetative state (VS) and the minimally conscious state (MCS), are challenging for neurologists. The locked-in syndrome (LiS) is sometimes confounded with these disorders by less experienced physicians. We aimed to investigate (1) the application of diagnostic knowledge, (2) attitudes concerning limitations of LST, and (3) further challenging aspects in the care of patients. A vignettebased online survey with a randomized presentation of a VS, MCS, or LiS case scenario was conducted among members of the German Society for Neurology. A sample
\end{abstract}

K. Kuehlmeyer $(\bowtie) \cdot$ R. J. Jox

Institute of Ethics, History and Theory of Medicine,

University of Munich, Lessingstrasse 2,

80336 Munich, Germany

e-mail: katja.kuehlmeyer@med.lmu.de

E. Racine $\cdot$ N. Palmour

Neuroethics Research Unit, Institut de recherches cliniques

de Montréal (IRCM), 110 avenue des Pins Ouest,

Montreal, QC H2W 1R7, Canada

E. Racine

Department of Medicine and Department of Social and

Preventive Medicine, Université de Montréal, Montreal, Canada

E. Racine

Departments of Neurology and Neurosurgery, Medicine and

Biomedical Ethics Unit, McGill University, Montreal, Canada

E. Hoster

Institute of Medical Informatics, Biometry, and Epidemiology,

University of Munich, Munich, Germany

G. D. Borasio

Service de Soins Palliatifs, Centre Hospitalier Universitaire

Vaudois (CHUV), University of Lausanne,

Lausanne, Switzerland of 503 neurologists participated (response rate 16.4\%). An accurate diagnosis was given by $86 \%$ of the participants. The LiS case was diagnosed more accurately $(94 \%)$ than the VS case $(79 \%)$ and the MCS case $(87 \%, p<0.001)$. Limiting LST for the patient was considered by 92,91 , and $84 \%$ of the participants who accurately diagnosed the VS, LiS, and MCS case $(p=0.09)$. Overall, most participants agreed with limiting cardiopulmonary resuscitation; a minority considered limiting artificial nutrition and hydration. Neurologists regarded the estimation of the prognosis and determination of the patients' wishes as most challenging. The majority of German neurologists accurately applied the diagnostic categories VS, MCS, and LiS to case vignettes. Their attitudes were mostly in favor of limiting life-sustaining treatment and slightly differed for MCS as compared to VS and LiS. Attitudes toward LST strongly differed according to circumstances (e.g., patient's will opposed treatment) and treatment measures.

Keywords End-of-life decisions .

Limitation of life-sustaining treatment - Diagnosis .

Vegetative state $\cdot$ Minimally conscious state

\section{Introduction}

The vegetative state (VS) and the minimally conscious state (MCS) are conditions that result from severe traumatic or non-traumatic brain injury, referred to as disorders of consciousness (DOC). In the VS, patients are awake, but do not show any signs of awareness, as judged by responsiveness [1, 2]. Recently, the European Task Force on DOC proposed the term "unresponsive wakefulness syndrome" (UWS) as a superior alternative to VS [3]. In the MCS, patients display limited, but reproducible 
evidence of awareness without having the ability to communicate reliably [4]. Several studies have revealed misdiagnosis rates of $40 \%$, in cases in which clinical bedside examination was compared to expert assessment or neurobehavioral testing [5-7]. Misdiagnosed patients were presumed to be in VS, but after a reassessment they were categorized as being in either a MCS or locked-in syndrome (LiS), where the patient is fully aware, has quadriplegia and aphonia or severe hypophonia, but is usually capable of communication by eye movements or blinking $[8,9]$. Inaccurate diagnosis is both a medical and an ethical problem. It biases prognostication and therapeutic strategy, and may lead to flawed decisions to withdraw or withhold life-sustaining treatment (LST) [2, 10].

The ethical justification of administering LST in these patients is a matter of intense ethical and societal debate, specifically with regard to the use of artificial nutrition and hydration, as in the public cases of Terri Schiavo and Eluana Englaro [11, 12]. Most surveys that investigated physicians' attitudes toward LST in DOC patients were conducted before the MCS was defined as a separate diagnostic category in 2002 [13-16]. A recently published European survey found that the diagnosis of VS or MCS influences ethical attitudes toward LST [17]. This survey, however, targeted a heterogeneous convenience sample of attendees at scientific conferences and asked for attitudes toward LST for patients in chronic VS or MCS ( $>1$ year). To our knowledge, no survey has investigated physicians' attitudes toward LST for patients in the LiS. A Japanese study used case vignettes to study physicians' attitudes toward LST in VS patients, but the patient's diagnosis was always provided. To our knowledge, no survey has used case vignettes instead of diagnostic terms to examine the participants' attitudes toward LST. By means of a web-based survey, we wanted to examine the attitudes of German neurologists regarding ethical issues in DOC and the LiS, and to assess the application of their diagnostic knowledge to a case vignette. We aimed to answer the following research questions: (1) how accurately do neurologists apply the diagnostic categories VS, MCS or LiS to hypothetical cases? (2) Do neurologists' attitudes toward LST for these patients differ according to the diagnosis of the patient? (3) Which ethically relevant aspects do neurologists evaluate as being the most challenging in the care of DOC and LiS patients?

\section{Methods}

\section{Questionnaire}

We developed a 37-item questionnaire in English. Three case vignettes (see Table 1), at the beginning of the questionnaire, were drafted by a neurologist (R.J.J) based on clinical consensus guidelines, and revised and verified by an international scientific advisory board of neurological DOC experts. The cases were presented randomly; each participant activating the link to the survey website received only one case and had an equal chance of getting one of the three cases.

After the presentation of the case, participants were asked: "if you had to assess the described case without detailed behavioral testing or technical diagnostic investigations, which diagnosis do you think fits best to the case?" Participants could choose among five diagnostic categories (VS, MCS, LiS, brain death, and coma) or give an alternative diagnosis in an open text field. No definitions of the VS, MCS, or LiS were provided. Participants were asked how certain they were on a numeric rating scale (NRS) $(0-10,10=$ extremely certain) about the diagnostic category that they assigned to the case. They were also asked to estimate the patient's functional outcome ("What do you think will be the patient's functional outcome in 6 months as measured by the modified Rankin scale?"). To assess the neurologists' conceptual understanding underlying the diagnosis, they were asked to judge which cognitive, emotional and behavioral capabilities such a patient has, choosing from a given list. Furthermore, the participants should estimate the quality of life of such a patient on a NRS, including the options of "no quality of life" and "I don't feel able to rate the patient's quality of life." Physicians' attitudes toward limiting LST were elicited by the following request: "Please specify: In the prior case lifesustaining treatment should be limited (a) never, (b) always, or (c) under certain circumstances." If participants chose "always" or "under certain circumstances," they had to specify these on given lists of ten different circumstances. If the circumstances did not apply to the case (like recovery of consciousness to the LiS) participants could choose alternatively "does not apply." In addition, participants were asked which specific treatment measures they would consider limiting. Finally, they were asked to rate the extent to which they find 13 ethically relevant aspects of caring for DOC patients challenging on a NRS. We asked for participants' characteristics such as gender, age, work environment, professional experience, and religion. Religion was analyzed according to religious practice and spiritual beliefs.

The questionnaire was pre-tested by five experts (four neurologists and a medical ethicist) and modified accordingly. We translated the final questionnaire into German using backward-forward translation [18]. Two German native speakers, who were involved in constructing the English survey (K.K., R.J.J.), translated the questionnaire independently from one another into German and a native English speaker translated the survey back into English. Inconsistencies were identified and led to a refinement of both the original English and the translated German 
Table 1 Case vignettes presented randomly to participants

Case $1^{\mathrm{a}}$

A 33-year-old man had a cardiac arrest with delayed resuscitation 4 months ago. Currently, he shows brainstem and spinal reflex movements, but no sign of purposeful movement. His eyes are open for several hours a day, but do not fixate objects or follow them when they move. He does not react consistently to verbal commands or questions. Sometimes a delayed stiffening of the legs and grimacing can be observed in reaction to sounds. He can breathe on his own

Case $2^{\mathrm{b}}$

A 35-year-old woman suffered a severe asthma attack with respiratory failure 4 months ago, causing severe brain injury. Currently, she shows brainstem and spinal reflexes and a severe spasticity, but no signs of purposeful movement. She does not need any breathing assistance. Her eyes are open for several hours a day, fixate objects and follow the nurses when they move around her. She does not react consistently to verbal commands or questions. When she is visited by her mother, she always seems more alert, and when her mother talks to her, she often smiles and utters single words. This does not happen when other persons talk to her

Case $3^{\mathrm{c}}$

A 36-year-old man had a brain stem hemorrhage 4 months ago. In the meantime he could be weaned from the ventilator. He does not move his limbs in any way and suffers from severe spasticity. During the day, his eyes are open for several hours. He consistently follows the command to blink once or twice, or to move his eyes up and down. A verbal utterance or groaning has not been observed

${ }^{a}$ Correct diagnosis: vegetative state (VS)

${ }^{b}$ Correct diagnosis: minimally conscious state (MCS)

${ }^{c}$ Correct diagnosis: locked-in state (LiS)

version. Online formatting was done with Survey Monkey software (Survey Monkey, Portland, OR, USA). The German questionnaire can be accessed by the link https://www. surveymonkey.com/s/UmfrageuberBewusstseinsstorungen (accessed 31 January 2012) without the need to type in a code.

\section{Data collection}

The study was approved by the research ethics committee of the local medical faculty. To include a representative cohort of German neurologists, we contacted the German Society for Neurology (Deutsche Gesellschaft für Neurologie), which facilitated the distribution of the survey link. Members of the society are physicians with a license to practice medicine and a small number $(\sim 0.1 \%)$ are medical students. Out of 6,673 members, we contacted all 3,073 members from whom the society had e-mail addresses and invited only physicians to participate. In the initial contact e-mail, we explained the purpose, objectives, and content of the study (medical and ethical aspects, diagnosis, prognosis, and treatment decisions for patients with disorders of consciousness), the voluntariness and data protection rules, the time it might take to fill out the questionnaire (10-20 min), a deadline for the participation, and provided the link to the survey website. Members with invalid addresses were excluded. The study was powered to detect a $15 \%$ difference in the attitudes toward limiting LST among the three cases, with a probability of $80 \%$. The data were gathered within a 4-week period from July to August 2011. To encourage participation we offered an opportunity to participate in a lottery, consisting of six prizes with a total value of $€ 1,500$. After 3 weeks, we sent a reminder and prolonged the participation period for an additional week. Data were gathered anonymously, and participants gave their informed consent.

Statistical analysis

Participants who made errors diagnosing the patients in the case vignettes were excluded from the analysis of their attitudes and their evaluation of challenges, because it was unclear whether they answered the remaining questions according to the vignette description or according to their inaccurate choice of diagnosis.

Data were downloaded from Survey Monkey and imported into IBM SPSS 19 statistics software. Pearson's $\chi^{2}$ test was performed to assess differences between categories. For numerical or ordinal data, the Mann-Whitney $U$ test was applied to compare two groups, and the KruskalWallis $H$ test was performed to compare three (or more) groups. Binary logistic regression analyses were used to examine associations between predictor variables and the accuracy of diagnosis, or the attitude toward limiting LST. Results were considered significant if $p<0.05$, and a trend to significance was reported if $p<0.10$. Following the recommendations of Perneger, $p$ values are descriptive and were not adjusted for multiple comparisons [19].

\section{Results}

Cohort and sample

Of the 3,073 members that were contacted, 517 participated in the online survey. Some society members 
Table 2 Demographic and professional characteristics of participants $(n=503)$

\begin{tabular}{|c|c|}
\hline Age (years), median; 1st 3rd quartile (range) & $43 ; 38,49(27-81)$ \\
\hline Experience (years) & $17 ; 11,21(<1-49)$ \\
\hline \multicolumn{2}{|l|}{ Gender, $n(\%)(n=31$ missing $)$} \\
\hline Female & $140(30)$ \\
\hline Male & $332(70)$ \\
\hline \multicolumn{2}{|l|}{ Primary discipline, $n(\%)(n=16$ missing $)$} \\
\hline Neurology & $479(98)$ \\
\hline Others (e.g., anesthesiology, psychiatry) & $8(2)$ \\
\hline \multicolumn{2}{|l|}{ Health care setting, $n(\%)^{\mathrm{a}}$} \\
\hline In-patient care & $370(74)$ \\
\hline Out-patient care & $173(34)$ \\
\hline \multicolumn{2}{|l|}{ Kind of care, $n(\%)^{\mathrm{a}}$} \\
\hline Acute care & $216(43)$ \\
\hline Rehabilitation care & $107(21)$ \\
\hline Long-term care & $39(8)$ \\
\hline \multicolumn{2}{|l|}{$\begin{array}{l}\text { Professional experience with VS patients, } n(\%) \\
\quad(n=25 \text { missing })\end{array}$} \\
\hline 0 cases & $15(3)$ \\
\hline$\leq 20$ cases & $261(55)$ \\
\hline$>20$ cases & $202(42)$ \\
\hline \multicolumn{2}{|c|}{$\begin{array}{l}\text { Professional experience with MCS patients, } n(\%) \\
\quad(n=40 \text { missing })\end{array}$} \\
\hline 0 cases & $39(8)$ \\
\hline$\leq 20$ cases & $249(54)$ \\
\hline$>20$ cases & $175(38)$ \\
\hline \multicolumn{2}{|l|}{$\begin{array}{l}\text { Professional experience with LiS patients, } n(\%) \\
\quad(n=32 \text { missing })\end{array}$} \\
\hline 0 cases & $54(11)$ \\
\hline$\leq 20$ cases & $356(76)$ \\
\hline$>20$ cases & $61(13)$ \\
\hline \multicolumn{2}{|l|}{ Religious practice, $n(\%)(n=25$ missing $)$} \\
\hline Practicing religion & $250(52)$ \\
\hline Not practicing religion & $228(48)$ \\
\hline \multicolumn{2}{|l|}{ Spiritual beliefs, $n(\%)(n=29$ missing $)$} \\
\hline Spiritual beliefs & $317(67)$ \\
\hline No spiritual beliefs & $157(33)$ \\
\hline
\end{tabular}

${ }^{a}$ Multiple answers permitted

mentioned their reasons for not participating: They either did not provide care for patients at all (due to retirement, to other professions, or being heads of the units or institutes), or they did not take care of patients with DOC. The 517 participants were randomly assigned to the VS $(n=175)$, MCS $(n=176)$, and $\operatorname{LiS}(n=166)$ case. Fourteen participants did not complete the questionnaire: 7 were assigned to the VS case, 5 to the MCS case, and 2 to the LiS case. A sample of 503 neurologists completed the online survey (response rate: 16.4\%); 168 participants

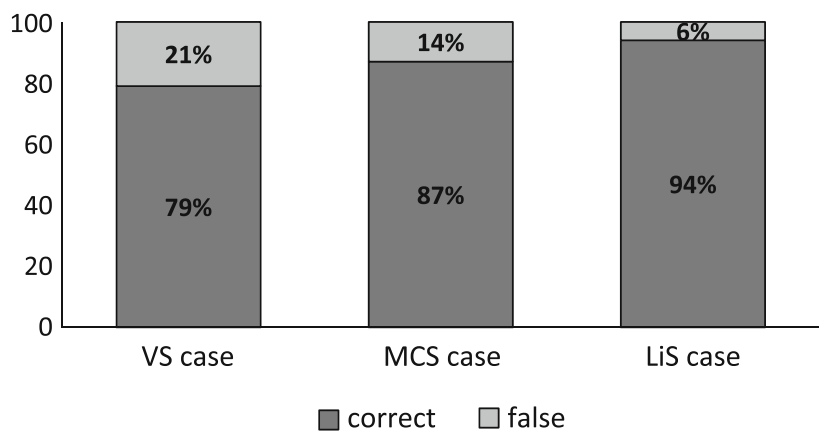

Fig. 1 Diagnostic accuracy as studied by three case vignettes on the vegetative state (VS), minimally conscious state (MCS), and lockedin syndrome (LiS). The $\chi^{2}$ test over all cases was significant $(p<0.001) . N=503$, VS case $(N=168)$, MCS case $(N=171)$, LiS case $(N=164)$; numbers may not add up to 100 due to rounding

(33\%) filled out the questionnaire with the VS case, 171 (34\%) the MCS-based version, and $164(33 \%)$ the LiSbased questionnaire. The cohort of 3,073 members with valid e-mail addresses was representative for all members $(6,673)$ according to age (members: mean 44 , standard deviation (SD) 10, range 25-94, and cohort: mean 45, SD 9 , range 25-87) and region of practice, but not gender. A lower percentage of women (28\%) was invited to participate than the actual percentage of women in the society $(38 \%)$. We analyzed whether gender had a significant influence on physicians' diagnostic accuracy or their attitudes toward limiting LST and describe these results in the respective sections. The demographic and professional characteristics of the participants are presented in Table 2 . The sample was representative for the society according to age (mean 44, SD 9, range 27-81).

\section{Application of diagnostic knowledge}

Overall, $86 \%(n=434)$ of the participants chose the correct diagnostic category. Of those participants who evaluated the VS case, $79 \%$ gave the diagnosis VS, $18 \%$ chose the diagnosis MCS, one participant chose coma (1\%), and $2 \%$ chose LiS. Of the participants who received the MCS case, $87 \%$ gave the diagnosis MCS, $4 \%$ chose VS, $7 \%$ chose LiS, and $2 \%$ chose the option to suggest an alternative diagnosis (e.g., severe anoxic brain injury). Participants with the LiS case chose the diagnosis LiS (94\%), MCS (4\%), VS (2\%), and one participant chose the option "other." The rate of accuracy differed significantly $(p<0.001)$ according to the three case vignettes (see Fig. 1).

In total, $83 \%$ of the female participants compared to $88 \%$ of the male participants accurately diagnosed the cases $(p=0.14)$. Participants who erred were slightly less certain about their diagnostic accuracy than participants who gave the correct answer (median 8 vs. 9 on a NRS, $p<0.001)$. 
Professional experience in years, with patients with DOC or in rehabilitation care

Neurologists with more years of professional experience had a slightly lower chance of misdiagnosing the MCS case (OR for 1 year more: 0.9 ; CI $0.9-1.0 ; p<0.05$ ), but professional experience had no significant influence on the accuracy of the neurologists' application of the diagnostic categories to the VS or LiS vignettes $(p=0.23, p=0.69)$.

Of the participants who received the VS case and gave information on their experience with VS $(n=159$, missing data: $n=9$ ), $76 \%$ of the neurologists who cared for less than 20 VS patients, $(n=96 ; 60 \%)$ diagnosed the VS case accurately, not significantly different from the $84 \%$ of those who cared of more than 20 patients $(n=63,40 \%$; $p=0.22$ ). However, in the group of participants who received the MCS case $(n=164$, missing data: $n=7), 93 \%$ of those who were more experienced in the care of VS patients ( $n=74,45 \%$ ) chose the correct diagnosis compared to $82 \%$ $(n=90,55 \%)$ of those who were less experienced $(p=0.04)$. In the VS case, $79 \%$ of the participants who were more experienced in the care of MCS patients $(n=56,36 \%)$ chose the accurate diagnosis, being equal to the group of participants who were less experienced in the care of MCS patients $(n=99,64 \% ; p=0.975)$. Yet, being highly experienced in the care of MCS patients was helpful in choosing the right diagnostic category for the MCS patient $(n=159$, missing data: 12). Out of those who had cared for more than 20 patients ( $n=64,40 \%) 95 \%$ diagnosed the case accurately compared to $84 \%$ of those who cared for less than 20 patients $(p=0.03)$. The accuracy rates of those working in a rehabilitation setting $(n=107)$ for the patients in VS $(72 \%)$, MCS (89\%), or LiS (91\%) did not significantly differ from the accuracy rate of those who did not work in a rehabilitation setting $(80 \%, 86 \%, 95 \% ; p=0.30 ; p=0.64 ; p=0.49)$.

We continued our data analysis with participants who accurately applied the diagnostic knowledge to the cases (from now on referred to as the VS group: $n=132$, MCS group: $n=148$, and LiS group: $n=154$ ).

\section{Patients' capabilities}

The percentage of neurologists agreeing with the presence of cognitive, emotional, and behavioral capabilities in the described patients are displayed in Table 3. Neurologists had different beliefs about which capabilities patients with VS, MCS, and LiS have. Disagreement was highest in the MCS case. Neurologists generally agreed that patients like the LiS patient were aware of themselves and their surroundings, and that the VS patients were not. Half of the neurologists agreed that MCS patients were aware; half of them did not. Within the respective cases, however, we found inconsistent answers. Most neurologists thought that
VS patients are not aware, yet a large proportion of them simultaneously stated that VS patients feel pain and experience hunger and thirst. Only $61 \%$ of neurologists thought that LiS patients could feel touch.

Table 3 Frequency of agreement with capabilities of a patient in the respective condition as judged by neurologists

\begin{tabular}{llll}
\hline Frequency (\%) & $\begin{array}{l}\text { VS group } \\
(n=132)^{\mathrm{a}}\end{array}$ & $\begin{array}{l}\text { MCS } \\
\text { group } \\
(n=148)^{\mathrm{a}}\end{array}$ & $\begin{array}{l}\text { LiS group } \\
(n=154)^{\mathrm{a}}\end{array}$ \\
\hline Being aware of themselves & 9 & 54 & 94 \\
Being aware of surroundings & 6 & 57 & 94 \\
Feeling pain & 77 & 96 & 86 \\
Smelling odors & 35 & 78 & 85 \\
Tasting flavor of food/drinks & 29 & 77 & 63 \\
Feeling touch & 67 & 94 & 61 \\
Having emotions & 35 & 87 & 93 \\
Recognizing their name & 12 & 67 & 92 \\
Recognizing people & 13 & 85 & 95 \\
Experiencing hunger/thirst & 46 & 92 & 83 \\
Having sexual desires & 13 & 47 & 68 \\
Understanding what & 8 & 39 & 93 \\
$\quad$ others say & & & \\
Having thoughts & 23 & 72 & 97 \\
Experiencing dreams & 36 & 76 & 90 \\
Remembering experiences & 13 & 54 & 92 \\
Storing new information & 8 & 32 & 85 \\
Expressing desires & 2 & 20 & 70 \\
Interacting with others & 8 & 57 & 86 \\
\hline
\end{tabular}

VS vegetative state, MCS minimally conscious state, LiS locked-in syndrome

${ }^{\text {a }}$ Those who correctly diagnosed the patients in the respective cases

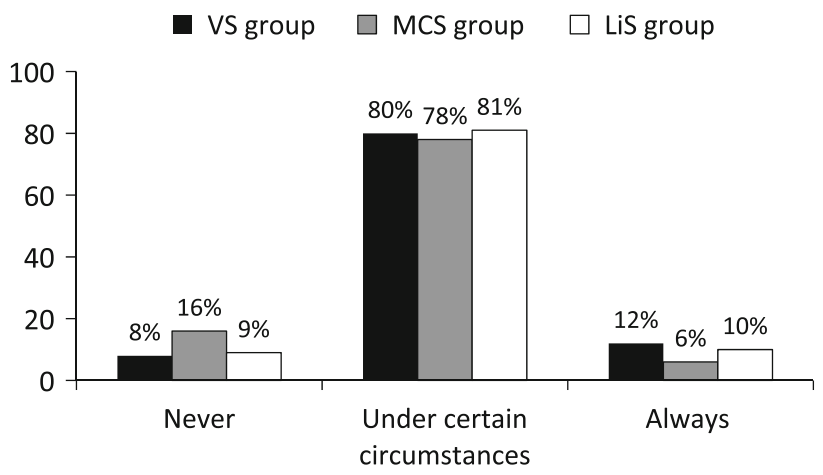

Fig. 2 Attitudes of those participants who accurately diagnosed the respective cases toward the limitation of life-sustaining treatment: "In the prior case life-sustaining treatment should be limited...?" Overall there was a trend toward significant differences $(p=0.09)$. Differences between the attitudes for VS and MCS are statistically significant ( $p=0.04, \chi^{2}$ test). $N=434$, VS group $(N=132)$, MCS group $(N=148)$, LiS group $(N=154)$; missing data: VS group $n=1 ;$ MCS group $n=1$, LiS group $n=5$ 
Attitudes toward limitation of life-sustaining treatment

The frequencies of whether LST should be limited for the patient in the case vignette are presented in Fig. 2. The attitudes did not differ among the three cases of VS, MCS, and LiS, but there was a statistical trend $(p=0.09)$. While there were no significant differences between the VS and the LiS group ( $p=0.82$ ) or the MCS and the LiS group
( $p=0.11)$, fewer participants would limit LST in the MCS case compared to the VS case $(p=0.04)$.

\section{Circumstances in support of limiting LST}

Table 4 shows how many participants agreed with limiting LST under certain circumstances, with the agreement scaled on a five-point rating scale. The particular

Table 4 Distribution and level of agreement (in \%) with limiting life-sustaining treatment under certain circumstances depending on the case groups

\begin{tabular}{|c|c|c|c|c|c|c|c|c|c|}
\hline \multicolumn{4}{|l|}{ Agreement $(\%)$} & \multicolumn{6}{|c|}{ Rating } \\
\hline & & & & \multicolumn{6}{|c|}{$1=$ extremely weak, $5=$ extremely strong } \\
\hline Circumstances & Groups $^{\mathrm{a}}$ & Median & $n$ & 1 & 2 & 3 & 4 & 5 & $p$ \\
\hline \multirow[t]{3}{*}{ Patient's will is opposed to LST } & VS & 5 & 116 & 1 & 1 & 3 & 11 & 85 & 0.04 \\
\hline & MCS & 5 & 121 & 1 & 3 & 4 & 22 & 70 & \\
\hline & LiS & 5 & 134 & 2 & 1 & 3 & 19 & 75 & \\
\hline \multirow[t]{3}{*}{ Patient suffers additional fatal disease (e.g., cancer) } & VS & 5 & 116 & 3 & 4 & 5 & 20 & 68 & 0.05 \\
\hline & MCS & 5 & 118 & 0 & 6 & 8 & 29 & 57 & \\
\hline & $\mathrm{LiS}$ & 5 & 128 & 4 & 7 & 12 & 23 & 55 & \\
\hline \multirow[t]{3}{*}{ Surrogate decision maker refuses consent to LST } & VS & 4 & 117 & 1 & 11 & 22 & 31 & 35 & 0.001 \\
\hline & MCS & 4 & 119 & 9 & 12 & 20 & 36 & 24 & \\
\hline & LiS & 4 & 132 & 10 & 13 & 27 & 38 & 13 & \\
\hline \multirow[t]{3}{*}{ No improvement after 1 year or longer } & VS & 4 & 107 & 10 & 11 & 25 & 23 & 30 & $<0.001$ \\
\hline & MCS & 3 & 115 & 20 & 18 & 22 & 25 & 15 & \\
\hline & LiS & 2 & 123 & 26 & 29 & 24 & 15 & 7 & \\
\hline \multirow[t]{3}{*}{ No chance for recovery of consciousness ${ }^{b}$} & VS & 4 & 111 & 5 & 14 & 15 & 23 & 43 & 0.06 \\
\hline & MCS & 4 & 115 & 8 & 15 & 16 & 26 & 36 & \\
\hline & LiS & 4 & 123 & 19 & 8 & 16 & 29 & 28 & \\
\hline \multirow[t]{3}{*}{ No chance for recovery of communication ${ }^{2}$} & VS & 3 & 108 & 7 & 19 & 27 & 27 & 20 & 0.01 \\
\hline & MCS & 3 & 116 & 13 & 23 & 30 & 20 & 15 & \\
\hline & $\mathrm{LiS}$ & 3 & 107 & 22 & 16 & 32 & 18 & 12 & \\
\hline \multirow[t]{3}{*}{ Patient obviously suffers intensely } & VS & 3 & 109 & 8 & 15 & 31 & 28 & 17 & 0.19 \\
\hline & MCS & 3 & 117 & 11 & 20 & 26 & 31 & 13 & \\
\hline & $\mathrm{LiS}$ & 2 & 127 & 13 & 22 & 25 & 28 & 12 & \\
\hline \multirow[t]{3}{*}{ If elderly (e.g., 70 years or older) } & VS & 3 & 102 & 18 & 28 & 30 & 17 & 7 & 0.003 \\
\hline & MCS & 3 & 115 & 16 & 24 & 26 & 23 & 12 & \\
\hline & $\mathrm{LiS}$ & 2 & 116 & 29 & 28 & 25 & 12 & 6 & \\
\hline \multirow[t]{3}{*}{ No chance for recovery without disability } & VS & 2 & 103 & 44 & 27 & 15 & 9 & 6 & 0.55 \\
\hline & MCS & 2 & 111 & 47 & 25 & 23 & 3 & 2 & \\
\hline & $\mathrm{LiS}$ & 1 & 121 & 51 & 24 & 11 & 11 & 3 & \\
\hline \multirow[t]{3}{*}{ Resources are scarce and costs high } & VS & 2 & 100 & 46 & 30 & 17 & 5 & 2 & 0.03 \\
\hline & MCS & 1 & 113 & 55 & 21 & 14 & 6 & 4 & \\
\hline & $\mathrm{LiS}$ & 1 & 116 & 65 & 21 & 10 & 3 & 2 & \\
\hline
\end{tabular}

LST Life-sustaining-treatment

From left to right: circumstances under which ${ }^{\text {a }}$ those who correctly diagnosed the patients in the respective cases (VS group: $n=132$, MCS group: $n=148$, and LiS group: $n=154$ ) agree with limiting LST; $N$ numbers of participants who rated the agreement with LST under specific circumstances, frequency of participants (in \%) who chose the respective number

b If circumstances do not apply to the case (here to LiS), participants could choose "does not apply." Kruskal-Wallis test; numbers may not add to 100 due to rounding 
circumstances led to differing attitudes toward limiting LST. Note that the participants who said they would never limit LST according to the case in the prior question skipped this question and the option "does not apply" was provided for the circumstances that did not apply to the patient in the respective case (such as no chance of recovery of consciousness to the LiS case).

Overall, fewer female participants who correctly diagnosed the cases $(n=115)$ gave the answer to never $(9 \%)$ or always limit (4\%) LST than did male participants $(n=292$; $12 \%, 12 \% ; p<0.05)$. There were significant gender differences in the willingness to limit LST under certain circumstances (see Table 5). More men than women agreed extremely strongly to limit LST if the patient suffers from an additional fatal disease or if there is no chance to recover communication. Yet more women agreed to limit LST if resources were scarce and costs were high.

\section{Treatment measures}

Figure 3 shows the frequency of agreement with the limitation of particular treatment measures. For most measures, the readiness to limit treatment was highest in the VS group, lower in the MCS group, and lowest in the LiS group. Significant differences between the three groups concerned artificial respiration $(p=0.02)$, surgery $(p=0.02)$, and administration of antibiotics $(p<0.05)$.

Participants who correctly diagnosed the cases were also asked whether they would make the same decisions for themselves if they were in the situation of the patient in the case vignette $(n=417)$. The majority $(71 \%)$ would want the same decisions to be made for them, $29 \%$ would favor less intensive LST measures, and only $1 \%$ would choose more intensive LST for them than they considered for the patient in the case vignette.

Table 5 Distribution and level of agreement (in \%) with limiting life-sustaining treatment under certain circumstances depending on the participant's gender

\begin{tabular}{|c|c|c|c|c|c|c|c|c|c|}
\hline \multicolumn{4}{|l|}{ Agreement to limit LST: } & \multicolumn{6}{|c|}{$1=$ extremely weak, $5=$ extremely strong } \\
\hline Circumstances & Gender $^{\mathrm{a}}$ & Median & $N$ & $1(\%)$ & $2(\%)$ & $3(\%)$ & $4(\%)$ & $5(\%)$ & $p$ \\
\hline \multirow[t]{2}{*}{ Patient's will is opposed to LST } & Male & 5 & 251 & 2 & 1 & 2 & 16 & 79 & 0.08 \\
\hline & Female & 5 & 104 & 1 & 2 & 6 & 21 & 70 & \\
\hline \multirow[t]{2}{*}{ Patient suffers from additional fatal disease } & Male & 5 & 252 & 2 & 4 & 8 & 24 & 62 & 0.03 \\
\hline & Female & 5 & 100 & 3 & 10 & 10 & 26 & 51 & \\
\hline \multirow[t]{2}{*}{ Surrogate decision maker refuses consent to LST } & Male & 4 & 249 & 6 & 13 & 23 & 35 & 24 & 0.76 \\
\hline & Female & 4 & 98 & 8 & 9 & 27 & 34 & 22 & \\
\hline \multirow[t]{2}{*}{ No improvement after 1 year or longer } & Male & 3 & 237 & 19 & 20 & 22 & 21 & 19 & 0.46 \\
\hline & Female & 3 & 93 & 20 & 18 & 27 & 22 & 13 & \\
\hline \multirow[t]{2}{*}{ No chance for recovery of consciousness ${ }^{b}$} & Male & 4 & 221 & 9 & 12 & 16 & 24 & 39 & 0.19 \\
\hline & Female & 4 & 92 & 13 & 13 & 14 & 30 & 30 & \\
\hline \multirow[t]{2}{*}{ No chance for recovery of communication ${ }^{\mathrm{b}}$} & Male & 3 & 225 & 12 & 15 & 30 & 26 & 17 & $<0.001$ \\
\hline & Female & 3 & 93 & 22 & 28 & 29 & 10 & 12 & \\
\hline \multirow[t]{2}{*}{ Patient obviously suffers intensely } & Male & 3 & 249 & 12 & 19 & 28 & 29 & 12 & 0.33 \\
\hline & Female & 3 & 98 & 10 & 19 & 24 & 30 & 17 & \\
\hline \multirow[t]{2}{*}{ If elderly (e.g., 70 years or older) } & Male & 3 & 231 & 23 & 25 & 28 & 17 & 8 & 0.62 \\
\hline & Female & 3 & 89 & 18 & 30 & 25 & 19 & 8 & \\
\hline \multirow[t]{2}{*}{ No chance for recovery without disability } & Male & 2 & 234 & 45 & 26 & 16 & 9 & 5 & 0.21 \\
\hline & Female & 1,5 & 88 & 50 & 26 & 18 & 5 & 1 & \\
\hline \multirow[t]{2}{*}{ Resources are scarce and costs high } & Male & 1 & 228 & 60 & 21 & 14 & 4 & 2 & 0.002 \\
\hline & Female & 2 & 88 & 40 & 33 & 15 & 8 & 5 & \\
\hline
\end{tabular}

LST life-sustaining treatment

From left to right: circumstances under which ${ }^{\text {a }}$ those who correctly diagnosed the patients in the respective cases and are male $(N=292)$ or female $(N=116)$ agreed with limiting LST; $N$ numbers of participants who rated their agreement with LST under specific circumstances. Values in the table represent the distribution of participant's responses on the rating scale

b If circumstances do not apply to the case (here to LiS), participants could choose "does not apply." Mann-Whitney $U$ test; numbers may not add to 100 due to rounding 
Fig. 3 Forms of life-sustaining treatment that neurologists who gave the accurate diagnosis would consider limiting (under certain circumstances or always). The bars indicate the percentage of respondents in each diagnostic group: VS (black), MCS (grey), and LiS (white). $n=434$, VS group $(n=132)$, MCS group

$(n=148)$, LiS group

$(n=154)$; asterisks significant differences among the three groups of respondents to the cases, using Pearson's $\chi^{2}$ test $(p<0.05$; intubation/ ventilation: $p=0.02$, surgical treatment: $p=0.02$, antibiotic treatment: $p<0.05$ )

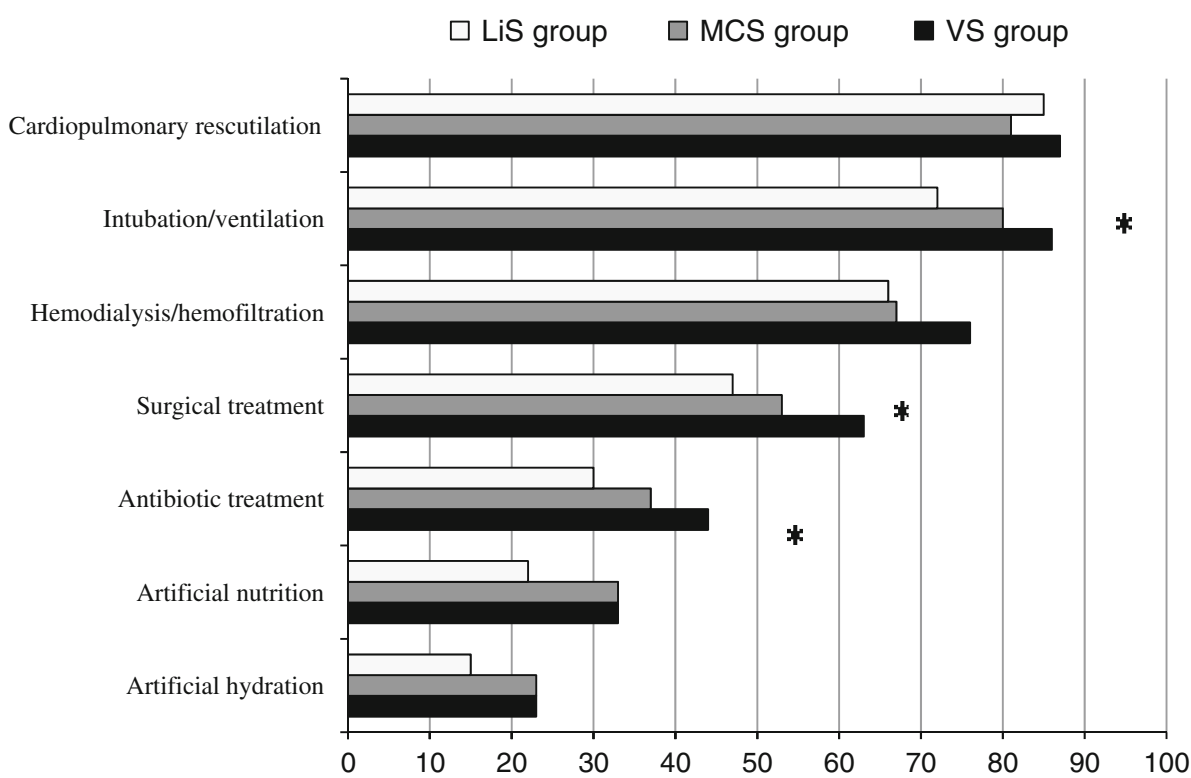

Significantly fewer female neurologists were willing to limit the use of antibiotics (30\%), artificial nutrition (22\%), and artificial hydration $(10 \%)$ than were male neurologists (40\%; 33\%; 25\%; $p=0.047, p=0.032, p=0.01)$. There were no significant gender differences in regard to the other therapeutic measures (cardiopulmonary resuscitation: 86 vs. $88 \%, p=0.60$; intubation and ventilation: 81 vs. $78 \%$, $p=0.53$; hemodialysis: 71 vs. $96 \%, p=0.70$; surgery: 57 vs. $52 \%, p=0.38$ ).

\section{Quality of life, prognosis, religion, and attitudes toward} LST

The option "I don't feel able to rate the patient's quality of life" was chosen by $32 \%$ of the participants $(n=172)$, the lowest amount being in the VS group (28\%), followed by the LiS (38\%), and MCS (39\%) group. The option that the patient had no quality of life was chosen by $14 \%$ in the VS group, $1 \%$ in the MCS group, and $3 \%$ in the LiS group. The median quality of life of the VS patient ( 1 ; span $0-4)$ and LiS patient (1; span 0-9) was rated lower than that of the MCS patient (2; span 0-7), and the three groups differed significantly $(p<0.001)$.

Only $3 \%$ of those who accurately diagnosed the VS case and $10 \%$ of those who diagnosed the LiS expected a better outcome (modified Rankin scale 4-0) compared to $25 \%$ of those who correctly diagnosed the MCS case $(p<0.001)$. The others expected severe disability (modified Rankin scale 5).

Of those who practiced a religion and diagnosed the patient correctly $(n=213), 6 \%$ would always limit LST in the respective case, $13 \%$ never, and $81 \%$ would limit treatment under circumstances, significantly different from those who did not practice a religion $(n=200)$, where $13 \%$ would always limit LST, 9\% never, and $78 \%$ under certain circumstances $(p=0.03)$. Of those who had spiritual beliefs in the existence of god, and diagnosed the patient correctly $(n=274), 6 \%$ would always limit LST, $11 \%$ never, and $83 \%$ under circumstances. Of those who did not have spiritual beliefs, and diagnosed the case correctly $(n=136), 16 \%$ would always limit LST, $10 \%$ never, and $74 \%$ under certain circumstances $(p=0.01)$.

Appraisal of ethical challenges

Table 6 displays how the participants judged different ethical challenges in the care of DOC patients. Prognosticating recovery and determining the patient's wishes were seen as extremely challenging for all three conditions. The least challenging issues were reaching an agreement as a team and multidisciplinary discussions. Overall, there were only slight differences among the three conditions. Some of the aspects seem to be a bit more challenging in one condition than another one, such as applying a surrogate's decision in VS compared to LiS cases.

\section{Discussion}

In this study, we used case vignettes instead of commonly used diagnostic terms $[13-15,20,21]$ to investigate neurologists' attitudes toward ethical issues that arise in the care of DOC and LiS patients. The overall accuracy in the application of diagnostic knowledge of DOC patients was found to be high in our vignette-based survey (79-86.5\%). 
Table 6 Appraisal of ethical challenges in the decision-making process for patients like the patient in the presented case

\begin{tabular}{|c|c|c|c|c|c|}
\hline Median (1st, 3rd quartile) on NRS (0-10) & Missing data $(n)^{\mathrm{b}}$ & VS group ${ }^{a}$ & MCS group ${ }^{a}$ & LiS group ${ }^{a}$ & $p$ \\
\hline Making prognosis and predicting recovery & 17 & $8(7,10)$ & $9(8,10)$ & $8(6.25,10)$ & 0.12 \\
\hline Determining patient's wishes & 17 & $8(7,10)$ & $8(7,10)$ & $9(8,10)$ & 0.03 \\
\hline Deciding for patient in absence of surrogate & 18 & $8(7,10)$ & $8(6,10)$ & $8(7,10)$ & 0.29 \\
\hline Discontinuing LST & 19 & $8(5,10)$ & $8(5,10)$ & $7(6,10)$ & 0.16 \\
\hline Making correct diagnosis & 15 & $7(4,9)$ & $7(3.5,8)$ & $7(3,9)$ & 0.58 \\
\hline Accompanying family members in decisions & 17 & $7(6,9)$ & $7(5,8)$ & $8(6,9)$ & 0.01 \\
\hline Applying a decision made by surrogate & 20 & $7(5,8)$ & $5(4,8)$ & $7(3,9)$ & 0.001 \\
\hline Evaluating resource allocation & 26 & $7(4,9)$ & $7(5,9)$ & $6(3,9)$ & 0.049 \\
\hline Assessing medical futility & 21 & $7(5,8)$ & $7(5,8)$ & $7(6,8)$ & 0.75 \\
\hline Finding long-term care & 21 & $6(4,8)$ & $6(3,8)$ & $6(3,8)$ & 0.46 \\
\hline Accompanying clients through staff rotations & 21 & $6(3.5,8)$ & $6(5,7)$ & $6(5,9)$ & 0.28 \\
\hline Multidisciplinary discussions for decisions & 17 & $5(3,7)$ & $5(2,8)$ & $5(3,8)$ & 0.39 \\
\hline Reaching an agreement as a team & 17 & $5(3,7)$ & $5(3,8)$ & $6(4,8)$ & 0.06 \\
\hline
\end{tabular}

a Those who correctly diagnosed the patients in the respective cases; $n=434$, VS group $(n=132)$, MCS group $(n=148)$, LiS group $(n=154)$; Kruskal-Wallis test

b Missing data: sum of all cases

Our approach can only be cautiously compared to studies verifying patients' diagnoses by clinical assessment or structured neurobehavioral examination. To compare the accuracy rates, we should not refer to misdiagnosis of case vignettes, but to misdiagnosis of diagnostic categories: how many of those who diagnosed VS actually had the VS case? If we recalculate the data accordingly, misdiagnosis in our study was between 7\% (VS) and 20\% (MCS), which is lower than in the clinical studies $(37-43 \%$ of the patients diagnosed as VS are actually in a MCS or other condition) $[5,6,22]$. This may be explained by the differing methodological approach of our study. We targeted neurologists instead of following up on patients and comparing diagnosis made on the basis of clinical assessment with diagnosis on the basis structural neurobehavioral tests. Furthermore, we assessed the application of diagnostic knowledge by presenting a typical, briefly described case and offering a limited range of potential diagnoses to choose from. In our study, the VS case led to the highest error rate, and the error that most often occurred was overestimating the patient as being in a MCS, suggesting the need for greater training in distinguishing patients on the borderline of VS and MCS. The error of overestimating patients in the VS as being in the MCS was not described by Schnakers et al. [22]. One could argue that overestimating the patient's capabilities is an error that is more preferable than underestimating them when considering the best interest of the patient. However, the consequences could be positive and negative: more rehabilitation treatment could be provided to the patient and a longer timeframe could be awaited to declare the condition as chronic.
If the patient had anticipated a decision for the VS his autonomy would not be respected because of the misdiagnosis. Furthermore, the patients' family could develop unrealistic expectations for recovery, communication, or other outcomes, and it would cause expenses for ineffective treatment. We were unable to determine factors that reduce the probability for misdiagnosis for the VS case, but for the MCS case experience with patients and years of professional experience were of value, which suggests including exposure to these sorts of patients during training. That experience did not predict a more accurate application of diagnostic knowledge for the VS case, but for the MCS case, is surprising, and perhaps the VS case stating that the patient "inconsistently" follows commands was misleading. Although neurologists who gave the correct diagnosis were significantly more confident and certain about their diagnosis than those who erred, even the latter had a relatively high level of confidence in their diagnostic skills. This may be problematic because they will probably not seek further training or a second opinion.

The assessment of the patients' remaining capabilities (Table 3) provided insight into the neurologists' understanding of VS, MCS, and LiS. This transcends the task of applying a diagnostic category to a case vignette and touches on beliefs of what it is like to be in such a state [23]. According to the traditional medical concept, VS patients are not aware, MCS patients have a rudimentary, partial, or inconstant awareness, and LiS patients are fully aware of themselves and their surroundings [24]. The responses reflect this distinction, with only a small percentage of neurologists who believe that VS patients are aware and a 
small percentage that even negates awareness in the LiS. The neurologists in the MCS group are divided: half of them regard the described MCS patient as being aware and the other half does not. This may reflect the breadth of and the uncertainty about the clinical continuum that covers the category of MCS, which has recently been subdivided into MCS plus (with high-level behavioral responses like command following) and MCS minus (with low-level behavioral responses like visual pursuit) [25]. The results suggest that the evaluation of the patient's remaining capabilities is highly dependent on the neurologists' conceptual understanding of the syndrome. Interestingly, although awareness is usually regarded as a prerequisite to all other mental phenomena, many participants agreed that VS patients were unaware, but still thought that they were able to dream, have thoughts and emotions, and perceive gustatory and tactile stimuli, including pain. Studies using somatosensory-evoked potentials and positron emission tomography have shown that noxious stimuli activate the pain matrix in MCS patients just like in controls, but in VS patients it is activated to a far lesser extent and without functional connectivity [26, 27]. Consistent with these findings, almost all neurologists in our survey agreed that MCS patients experience pain. Yet, more than three quarters of participants assume that VS patients also experience pain and nearly half of them assume that VS patients also feel hunger and thirst. In the survey by Demertzi et al. [28] a lower number (56\% of the medical doctors) assumed that VS patients feel pain while an equally high number affirmed pain perception for MCS (96\%). Experience with patients' motor or vegetative reactions to noxious stimuli might have influenced the neurologists' assumptions. Such reactions are not necessarily a sign of conscious awareness, which is a prerequisite for the experience of pain. In a survey among LiS patients who were in a chronic condition (at least 1 year after a brainstem vascular accident), half of the participants experienced pain and two-thirds anxiety [29]. More studies in this area are clearly warranted. It would be interesting to compare neurologists' beliefs about the capabilities of LiS patients with the patients' self-assessments.

Over $90 \%$ of the participants would consider limiting LST for the VS and LiS patient at least under certain circumstances, but only $84 \%$ would consider it for MCS patients. Contrary to our expectations, there were no statistically significant differences in the attitudes toward limitation of LST among all three cases. The difference between MCS and VS is in agreement with the recent European survey done by Demertzi et al. [17], yet they found far lower rates of physicians' (i.e., medical professionals) agreement with treatment limitation (67\% for VS and $27 \%$ for MCS). The difference between the attitudes toward VS and MCS when selecting the attitudes of the participants from central Europe was still much larger than in our survey. While their survey asked about patients more than 1 year after injury, our vignettes referred to patients with non-traumatic injuries that occurred only 4 months prior. The use of case vignettes instead of diagnostic terms and the sample of clinical neurologists instead of attendees of scientific conferences might explain the different results of the two studies. Comparing our results to other surveys, we have to differentiate between attitudes toward treatment limitation in general or toward withdrawal of artificial nutrition and hydration in particular. Our results on VS are quite similar to the results of American, British, and Belgian surveys from the 1990s when comparing the willingness to limit treatment in general (88-91\% agreement to limit LST), but our participants were less willing to withdraw artificial nutrition and hydration [13-15]. Only 34\% of our participants, who accurately diagnosed the VS case, would withdraw artificial nutrition and only $23 \%$ would withdraw artificial hydration in the VS case. In the American, British, and Belgian surveys, 56-89\% considered the withdrawal of artificial nutrition and hydration appropriate. Even in an Italian survey from 2011 a higher percentage of the physicians (66\%) believed that the withdrawal of artificial nutrition and hydration to be appropriate depending on the patient's wish [30]. On the other hand, surveys from Japan, and an older German survey of 283 medical directors of neurological, neurosurgical, and rehabilitation departments reported much lower rates of agreement with limitation of treatment (30, $58 \%)$ and withdrawal of artificial nutrition and hydration $(3,16 \%)[16,20,31]$. Lanzerath et al. gave two reasons for this: (1) in Germany, artificial nutrition and hydration were considered to be a form of indispensable basic care and not a medical treatment measure that could be withdrawn; (2) the experience with the misuse of medicine during National Socialism has led to a higher sensibility for ethical concerns, especially regarding end-of-life decisions. There might also be additional reasons. If the law in a country explicitly allows limiting artificial nutrition and hydration in VS patients, like in Great Britain after the case of Tony Bland, this might influence the physicians' attitudes. Moreover, religiosity is a factor that influences treatment decisions [17], which was confirmed by our results. Another explanation could be found at the level of methods: most questionnaires provided only two options (yes or no), while we offered three answer alternatives and most participants chose the option "under certain circumstances." Although the sample of the German survey from 1997 is not directly equivalent to our sample, it can be hypothesized that the attitudes of neurologists have become more liberal since then, paralleling a process of liberalization in German medical law and ethics [32, 33].

The similar results on the attitudes toward LST in the VS and LiS group warrant the conclusion that the presence 
or absence of consciousness does not seem to be the basis for neurologists' decisions to limit LST, which is consistent with the arguments of Levy and Savulescu and Wilkinson et al. [34, 35]. It is surprising that so many neurologists agree with limiting LST for patients in the LiS. Lule et al. [36] reported that despite their extreme motor impairment, a significant number of LiS patients maintain a good quality of life that seems unrelated to their state of physical functioning. In the study by Bruno et al. [29] 58\% of the LiS patients declared they did not wish to be resuscitated in case of cardiac arrest, and 53\% had envisaged euthanasia, but only $7 \%$ had a current wish for euthanasia. The authors identified satisfied and dissatisfied subpopulations that also differed in symptoms of depression, anxiety, and in the time they had spent in the LiS. A delay of end-of-life decisions was suggested to allow patients with more recent injuries to adapt psychologically to the new situation. In our survey, the median estimated quality of life of the LiS patient was as high as the median quality of life of the VS patient. Prognosis of functional outcome could explain the decision for or against treatment limitation for the MCS case. Patients in the MCS are regarded as having a better prognosis than VS patients [37], but studies that examine the prognosis of MCS patients prospectively are rare [38], and clinicians often refer to single cases of remarkable late recoveries of MCS patients [11]. We showed that female participants tend to be more uniform in their attitudes (preferring treatment limitation under certain circumstances instead of "always" or "never"). In other surveys male gender was significantly associated with greater willingness to forego LST [39] and to discuss end-of-life decisions with competent patients [40]. The authors of the first study argued that female physicians were following care ethics rather than rights-based ethics.

There were more differences among the three cases when it came to the agreement with limiting LST under given circumstances and the concrete treatment measures. One of the strongest circumstances that led to agreement for limiting LST was that the patient's will opposed treatment. This is in accordance with the ethical principle of respect of patient autonomy [41]. Interestingly, patient autonomy was more often extremely strongly agreed upon in the VS case than in the MCS or LiS case, suggesting that indirectly diagnosis plays a role in the actualization of the patient's will. In German law, a patient's advance directive has to be respected. The refusal of treatment by the patient's surrogate decision maker is also binding [33]. The surrogate, however, has the obligation to decide according to the patient's will, yet in practice the patient's will might be overruled by other arguments such as the surrogate's expectation of the patient's recovery [42]. In our study, there was strong agreement with the limitation of treatment if the surrogate refuses consent, particularly in the VS case.
No improvement for more than 1 year was a stronger argument in the care of a VS patient, a mediocre argument in the care of a MCS patient, and a weaker argument in the care of a LiS patient. Opinions on the VS were consistent with conclusions of expert groups who consider VS as permanent 3 or 6 months after non-traumatic brain injury or a year after traumatic brain injury [43, 44]. Yet, the recommendations were criticized for including patients in their survival data who died primarily because their lifesustaining therapy was discontinued [38]. When the recommendations about the VS were made, the MCS had not been recognized as a diagnostic category, yet and no time frames are known to declare the MCS to be irreversible. Women were not in general less against treatment withdrawal than men. They agreed less than men with limiting treatment for patients who suffered from an additional fatal disease or who had no chance for recovery of communication, but they agreed more with limiting treatment if resources were scarce and costs high.

Age and resource scarcity were considered to influence LST decisions only slightly. We know from specific surveys and qualitative studies that these factors do indeed influence treatment decision making [45, 46]. Such factors may act implicitly (as a cause) but may not be explicitly acknowledged (as a reason). There is a tendency to answer these questions according to social desirability, and both ageism and rationing due to resource scarcity are still taboos in Germany.

Most participants considered forgoing cardiopulmonary resuscitation and mechanical ventilation. They were, however, reluctant to limit artificial nutrition or hydration. This pattern is well known from many studies on attitudes and actual practices of end-of-life decision-making [47, 48], including a recent survey of German intensive care clinicians [49]. We identified gender differences in the willingness to withhold antibiotic treatment, artificial nutrition and hydration. More women were reluctant to limit these treatment forms than men. To our knowledge, gender difference particularly in regard to the willingness to withdraw artificial and hydration in disorders of consciousness patients have not been described before. Decisions about artificial nutrition and hydration in DOC patients are still controversial issues for healthcare providers both in Europe and North America [10, 12]. Most countries' laws, including German law, do not differentiate between withdrawing or withholding artificial nutrition and hydration or any other form of LST.

That the majority of the neurologists would prefer the same treatment measures for themselves can be interpreted in two ways. It could be claimed that their decisions are value-driven or that they want the best treatment for their patients as they would want for themselves. Interestingly almost no one would prefer more treatment for themselves 
than for the patient, but $30 \%$ preferred more treatment for the patient than for themselves. Maybe they want to be more cautious about their patients than about themselves or perhaps to avoid feelings of guilt.

We found that determining the prognosis of potential recovery as well as determining the patient's wishes regarding the treatment in conditions such as VS, MCS, and LiS were the most ethically challenging issues for the participants of this study. This finding was not surprising given that the challenge of prognosis is a recurring theme in the literature on DOC, as well as in the care of severely ill neurological patients on the whole [10]. Identifying patients' treatment wishes is known to be one of the most difficult challenges for physicians, especially if the patients are incompetent and uncommunicative [50]. Advance directives may facilitate decisions in accordance with the patients' wishes, but as brain injuries are mostly unexpected and often strike young, healthy people, advance directives are rarely present for DOC patients. Even if they are available, their interpretation can be difficult [51]. Issues that were judged to be less challenging (e.g., finding long-term care placements, accompany families and treating patients within staff rotations, discussing treatment decisions in a multidisciplinary context) revolve around contextual or institutional factors. Contextual factors have been shown in different studies to influence physicians' decisions [52], but physicians may not be cognizant of them or fully acknowledge them [53]. Our results reflect how physicians themselves understand ethical challenges, which may not be congruent with their own practices or with the attitudes of family members or other healthcare providers [54]. The online survey provides an efficient and successful method for the measurement of knowledge and attitudes toward decision making for DOC patients that can be conducted in different countries, with physicians with different subspecialties and with members of other professions (e.g., nurses).

\section{Limitations}

Our e-mail survey had a moderate response rate, low in comparison with mailed surveys [55]. The fact that online surveys have lower response rates than mailed surveys is in accordance with a previous study with residents and faculty [56]. Compared to other online surveys with physicians, our response rate is acceptable (other surveys: 5\% [57], $13 \%$, [58], $72 \%$ of 68 active members of a professional society [59]). Our survey was relatively long, which may have put off potential participants. The society we accessed has over 6,000 members, and therefore diffusion of responsibility might also lower the response rate. Another problem was that we recruited during summer holidays. Some potential participants informed us that they did not fill in the questionnaire because they did not care for DOC patients. In spite of these caveats, the cohort in our study was still representative for the German Society of Neurology by age and region, and the sample representative by age, but not by gender. Statistical analysis showed that gender had no influence on diagnostic accuracy, but it had an influence on the attitudes toward the limitation of LST. It is possible that our survey overrepresented the perspective of male neurologists that seem to be more in favor of extreme answers (to always or never limit LST), as compared to the female participants considering treatment limitation under certain circumstances. To fully acknowledge gender differences in the attitudes toward treatment limitation the issue should be in the focus of following studies.

Members of other specialties such as anesthesiology, palliative medicine, rehabilitation medicine, and pediatrics were not included given our focus on neurology experts and our goal of measuring the application of diagnostic knowledge. These specialists could be included in further studies to understand differences between specialty physicians as well as differences between physicians and other healthcare providers. Other studies revealed that there are cultural differences in the attitudes toward treatment limitation; therefore, our results should be compared to those of other countries [60].

\section{Conclusion}

The application of diagnostic knowledge of VS, MCS, and LiS was accurately performed by most German neurologists. Their attitudes were mostly in favor of limiting lifesustaining treatment and slightly differed between MCS as compared to VS and LiS. Attitudes strongly differed under certain circumstances (e.g., patient's will opposed treatment) and according to treatment measures.

Acknowledgments We are very grateful to the members of our scientific advisory board (James L. Bernat, Georg Marckmann, Richard J. Riopelle) who advised on the study design and the survey construction, and gave feedback on the results. We thank the German Society for Neurology (Deutsche Gesellschaft für Neurologie) for their approval and support in accessing the sample of neurologists. Thanks to Catherine Rodrigue for bringing in her ideas into the questionnaire. We thank the research assistants Hannah Burley for the forward-translation of the questionnaire, Dorothee Wagner von Hoff for proofreading the manuscript, and Hendrik Terwort and Tobias Budick for administrative support. A special thanks to Monika Koegler and Monika Brandstaetter for helping with the statistics. This work stems from the "Neuroethics Project on Disorders of Consciousness" within the German-Canadian-Finnish Neuroethics Initiative 2009-2011, funded by the German Ministry for Education and Research (BMBF: FKZ 01GP0801) and the Canadian Institutes of 
Health Research (CIHR: Operating grant, New Investigator Award, and States of Mind Network).

Conflicts of interest The authors declare that they have no conflict of interest.

Open Access This article is distributed under the terms of the Creative Commons Attribution License which permits any use, distribution, and reproduction in any medium, provided the original author(s) and the source are credited.

\section{References}

1. Jennett B, Plum F (1972) Persistent vegetative state after brain damage. A syndrome in search of a name. Lancet 1(7753):734737

2. Bernat JL (2009) Chronic consciousness disorders. Annu Rev Med 60:381-392. doi:10.1146/annurev.med.60.060107.091250

3. Laureys S, Celesia GG, Cohadon F, Lavrijsen J, Leon-Carrion J, Sannita WG, Sazbon L, Schmutzhard E, von Wild KR, Zeman A, Dolce G (2010) Unresponsive wakefulness syndrome: a new name for the vegetative state or apallic syndrome. BMC Med 8:68. doi:10.1186/1741-7015-8-68

4. Giacino JT, Ashwal S, Childs N, Cranford R, Jennett B, Katz DI, Kelly JP, Rosenberg JH, Whyte J, Zafonte RD, Zasler ND (2002) The minimally conscious state: definition and diagnostic criteria. Neurology 58(3):349-353

5. Childs NL, Mercer WN, Childs HW (1993) Accuracy of diagnosis of persistent vegetative state. Neurology 43(8):1465-1467

6. Andrews K, Murphy L, Munday R, Littlewood C (1996) Misdiagnosis of the vegetative state: retrospective study in a rehabilitation unit. BMJ 313(7048):13-16

7. Schnakers C, Vanhaudenhuyse A, Giacino J, Ventura M, Boly M, Majerus S, Moonen G, Laureys S (2009) Diagnostic accuracy of the vegetative and minimally conscious state: clinical consensus versus standardized neurobehavioral assessment. BMC Neurol 9:35

8. Smith E, Delargy M (2005) Locked-in syndrome. BMJ 330(7488):406-409. doi:10.1136/bmj.330.7488.406

9. Recommendations for use of uniform nomenclature pertinent to patients with severe alterations in consciousness. American Congress of Rehabilitation Medicine (1995) Arch Phys Med Rehabil 76 (2):205-209

10. Racine E, Rodrigue C, Bernat JL, Riopelle R, Shemie SD (2010) Observations on the ethical and social aspects of disorders of consciousness. Can J Neurol Sci 37(6):758-768. doi:687U3054 7U2Q61Q6

11. Wijdicks EF (2006) Minimally conscious state vs. persistent vegetative state: the case of Terry (Wallis) vs. the case of Terri (Schiavo). Mayo Clin Proc 81(9):1155-1158

12. Luchetti M (2010) Eluana Englaro, chronicle of a death foretold: ethical considerations on the recent right-to-die case in Italy. J Med Ethics 36(6):333-335

13. Payne K, Taylor RM, Stocking C, Sachs GA (1996) Physicians' attitudes about the care of patients in the persistent vegetative state: a national survey. Ann Intern Med 125(2):104-110

14. Grubb A, Walsh P, Lambe N, Murrells T, Robinson S (1996) Survey of British clinicians' views on management of patients in persistent vegetative state. Lancet 348(9019):35-40

15. Dierickx K, Schotsmans P, Grubb A, Walsh P, Lambe N (1998) Belgian doctors' attitudes on the management of patients in persistent vegetative state (PVS): ethical and regulatory aspects. Acta Neurochir (Wien) 140(5):481-489
16. Asai A, Maekawa M, Akiguchi I, Fukui T, Miura Y, Tanabe N, Fukuhara S (1999) Survey of Japanese physicians' attitudes towards the care of adult patients in persistent vegetative state. J Med Ethics 25(4):302-308

17. Demertzi A, Ledoux D, Bruno MA, Vanhaudenhuyse A, Gosseries O, Soddu A, Schnakers C, Moonen G, Laureys S (2011) Attitudes towards end-of-life issues in disorders of consciousness: a European survey. J Neurol. doi:10.1007/s00415-010-5882-z

18. World Health Organization (WHO) Process of translation and adaptation of instruments. http://www.who.int/substance_abuse/ research_tools/translation/en/. Accessed 14 Nov 2011

19. Perneger TV (1998) What's wrong with Bonferroni adjustments. BMJ 316(7139):1236-1238

20. Lanzerath D, Honnefelder L, Feeser U (1998) Nationaler Bericht der europäischen Befragung: „Doctors' views on the management of patients in persistent vegetative state (PVS) "im Rahmen des Forschungsprojekts „The moral and legal issues surrounding the treatment and health care of patients in persistent vegetative state". Ethik Med 10:152-180

21. Demertzi A, Ledoux D, Bruno MA, Vanhaudenhuyse A, Gosseries O, Soddu A, Schnakers C, Moonen G, Laureys S (2011) Attitudes towards end-of-life issues in disorders of consciousness: a European survey. J Neurol 258(6):1058-1065. doi:10.1007/ s00415-010-5882-z

22. Schnakers C, Vanhaudenhuyse A, Giacino J, Ventura M, Boly M, Majerus S, Moonen G, Laureys S (2009) Diagnostic accuracy of the vegetative and minimally conscious state: clinical consensus versus standardized neurobehavioral assessment. BMC Neurol 9(1):35. doi:10.1186/1471-2377-9-35

23. Laureys S, Pellas F, Van Eeckhout P, Ghorbel S, Schnakers C, Perrin F, Berre J, Faymonville ME, Pantke KH, Damas F, Lamy M, Moonen G, Goldman S (2005) The locked-in syndrome: what is it like to be conscious but paralyzed and voiceless? Prog Brain Res 150:495-511. doi:10.1016/s0079-6123(05)50034-7

24. Bernat JL (2006) Chronic disorders of consciousness. Lancet 367(9517):1181-1192. doi:10.1016/S0140-6736(06)68508-5

25. Bruno MA, Vanhaudenhuyse A, Thibaut A, Moonen G, Laureys S (2011) From unresponsive wakefulness to minimally conscious PLUS and functional locked-in syndromes: recent advances in our understanding of disorders of consciousness. J Neurol. doi: 10.1007/s00415-011-6114-x

26. Laureys S, Faymonville ME, Peigneux P, Damas P, Lambermont B, Del Fiore G, Degueldre C, Aerts J, Luxen A, Franck G, Lamy M, Moonen G, Maquet P (2002) Cortical processing of noxious somatosensory stimuli in the persistent vegetative state. Neuroimage 17(2):732-741

27. Boly M, Faymonville ME, Schnakers C, Peigneux P, Lambermont B, Phillips C, Lancellotti P, Luxen A, Lamy M, Moonen G, Maquet P, Laureys S (2008) Perception of pain in the minimally conscious state with PET activation: an observational study. Lancet Neurol 7(11):1013-1020. doi:10.1016/S1474-4422(08) 70219-9

28. Demertzi A, Schnakers C, Ledoux D, Chatelle C, Bruno MA, Vanhaudenhuyse A, Boly M, Moonen G, Laureys S (2009) Different beliefs about pain perception in the vegetative and minimally conscious states: a European survey of medical and paramedical professionals. Prog Brain Res 177:329-338. doi: 10.1016/S0079-6123(09)17722-1

29. Bruno MA, Bernheim JL, Ledoux D, Pellas F, Demertzi A, Laureys S (2011) A survey on self-assessed well-being in a cohort of chronic locked-in syndrome patients: happy majority, miserable minority. BMJ Open 1(1):e000039. doi:10.1136/bmj open-2010-000039

30. Solarino B, Bruno F, Frati G, Dell'erba A, Frati P (2011) A national survey of Italian physicians' attitudes towards end-of-life decisions following the death of Eluana Englaro: reply to M.Y. 
Rady. Intensive Care Med 37(8):1394-1395. doi:10.1007/ s00134-011-2276-3

31. Solarino B, Bruno F, Frati G, Dell'erba A, Frati P (2011) A national survey of Italian physicians' attitudes towards end-of-life decisions following the death of Eluana Englaro. Intensive Care Med 37(3):542-549

32. Jox RJ, Michalowski S, Lorenz J, Schildmann J (2008) Substitute decision making in medicine: comparative analysis of the ethicolegal discourse in England and Germany. Med Health Care Philos 11(2):153-163. doi:10.1007/s11019-007-9112-0

33. Wiesing U, Jox RJ, Hessler HJ, Borasio GD (2010) A new law on advance directives in Germany. J Med Ethics 36(12):779-783. doi:10.1136/jme.2010.036376

34. Levy N, Savulescu J (2009) Moral significance of phenomenal consciousness. Prog Brain Res 177:361-370. doi:10.1016/s00796123(09)17725-7

35. Wilkinson DJ, Kahane G, Horne M, Savulescu J (2009) Functional neuroimaging and withdrawal of life-sustaining treatment from vegetative patients. J Med Ethics 35(8):508-511. doi: 10.1136/jme.2008.029165

36. Lule D, Zickler C, Hacker S, Bruno MA, Demertzi A, Pellas F, Laureys S, Kubler A (2009) Life can be worth living in locked-in syndrome. Prog Brain Res 177:339-351. doi:10.1016/S0079-6123 (09)17723-3

37. Luaute J, Maucort-Boulch D, Tell L, Quelard F, Sarraf T, Iwaz J, Boisson D, Fischer C (2010) Long-term outcomes of chronic minimally conscious and vegetative states. Neurology 75(3):246252. doi:10.1212/WNL.0b013e3181e8e8df

38. Bernat JL (2010) Current controversies in states of chronic unconsciousness. Neurology 75(18 Suppl 1):S33-S38. doi: 10.1212/WNL.0b013e3181fb35dd

39. Giannini A, Pessina A, Tacchi EM (2003) End-of-life decisions in intensive care units: attitudes of physicians in an Italian urban setting. Intensive Care Med 29(11):1902-1910. doi:10.1007/ s00134-003-1919-4

40. Mortier F, Bilsen J, Vander Stichele RH, Bernheim J, Deliens L (2003) Attitudes, sociodemographic characteristics, and actual end-of-life decisions of physicians in Flanders, Belgium. Med Decis Making 23(6):502-510. doi:10.1177/0272989X03260137

41. Beauchamp TL, Childress JF (2009) Principles of Biomedical Ethics. Oxford University Press, New York Oxford

42. Kuehlmeyer K (2012) How family caregivers' medical and moral assumptions influence decision making for patients in the vegetative state: a qualitative interview study. J Med Ethics (in press)

43. Medical aspects of the persistent vegetative state (2). The MultiSociety Task Force on PVS (1994). N Engl J Med 330 (22):1572-1579. doi: 10.1056/NEJM199406023302206

44. Royal College of Physicians (2003) The vegetative state: guidance on diagnosis and management. [Report of a working party of the Royal College of Physicians]. In: Royal College of Physicians, London

45. Frost DW, Cook DJ, Heyland DK, Fowler RA (2011) Patient and healthcare professional factors influencing end-of-life decisionmaking during critical illness: a systematic review. Crit Care Med 39(5):1174-1189. doi:10.1097/CCM.0b013e31820eacf2

46. Strech D, Marckmann G (2010) Is there health care rationing in German hospitals? How exactly do we know and why should it not be the most important question? Dtsch Med Wochenschr 135(30):1498-1502. doi:10.1055/s-0030-1262439
47. Vincent JL (1999) Forgoing life support in western European intensive care units: the results of an ethical questionnaire. Crit Care Med 27(8):1626-1633

48. Asch DA, Christakis NA (1996) Why do physicians prefer to withdraw some forms of life support over others? Intrinsic attributes of life-sustaining treatments are associated with physicians' preferences. Med Care 34(2):103-111

49. Jox RJ, Krebs M, Fegg M, Reiter-Theil S, Frey L, Eisenmenger W, Borasio GD (2010) Limiting life-sustaining treatment in German intensive care units: a multiprofessional survey. J Crit Care 25(3):413-419. doi:10.1016/j.jcrc.2009.06.012

50. Hurst SA, Perrier A, Pegoraro R, Reiter-Theil S, Forde R, Slowther AM, Garrett-Mayer E, Danis M (2007) Ethical difficulties in clinical practice: experiences of European doctors. J Med Ethics 33(1):51-57. doi:10.1136/jme.2005.014266

51. Winter L, Parks SM, Diamond JJ (2010) Ask a different question, get a different answer: why living wills are poor guides to care preferences at the end of life. J Palliat Med 13(5):1-5

52. Ganz FD, Benbenishty J, Hersch M, Fischer A, Gurman G, Sprung CL (2006) The impact of regional culture on intensive care end of life decision making: an Israeli perspective from the ETHICUS study. J Med Ethics 32(4):196-199. doi:10.1136/jme. 2005.012542

53. Racine E, Dion MJ, Wijman CA, Illes J, Lansberg MG (2009) Profiles of neurological outcome prediction among intensivists. Neurocrit Care 11(3):345-352. doi:10.1007/s12028-009-9225-9

54. Rodrigue C, Riopelle R, Bernat J, Racine E Perspectives and experience of healthcare professionals on diagnosis, prognosis, and end-of-life decision making in patients with disorders of consciousness. Neuroethics: 1-12. doi: 10.1007/s12152-0119142-4

55. Asch DA, Jedrziewski MK, Christakis NA (1997) Response rates to mail surveys published in medical journals. J Clin Epidemiol 50(10):1129-1136 pii: S0895-4356(97)00126-1

56. Akl EA, Maroun N, Klocke RA, Montori V, Schunemann HJ (2005) Electronic mail was not better than postal mail for surveying residents and faculty. J Clin Epidemiol 58(4):425-429. doi:10.1016/j.jclinepi.2004.10.006

57. Obermann K, Muller P (2007) [Quality management in private practice. A nationwide survey in Germany]. Urologe A 46 (8):851, 854-858, 860-853. doi: 10.1007/s00120-007-1377-7

58. Markandaya M, Thomas KP, Jahromi B, Koenig M, Lockwood AH, Nyquist PA, Mirski M, Geocadin R, Ziai WC (2012) The role of neurocritical care: a brief report on the survey results of neurosciences and critical care specialists. Neurocrit Care 16(1):72-81. doi:10.1007/s12028-011-9628-2

59. McDonagh DL, Olson DM, Kalia JS, Gupta R, Abou-Chebl A, Zaidat OO (2010) Anesthesia and sedation practices among neurointerventionalists during acute ischemic stroke endovascular therapy. Front Neurol 1:118. doi:10.3389/fneur.2010.00118

60. Sprung CL, Woodcock T, Sjokvist P, Ricou B, Bulow HH, Lippert A, Maia P, Cohen S, Baras M, Hovilehto S, Ledoux D, Phelan D, Wennberg E, Schobersberger W (2008) Reasons, considerations, difficulties and documentation of end-of-life decisions in European intensive care units: the ETHICUS Study. Intensive Care Med 34(2):271-277. doi:10.1007/s00134-007-0927-1 